\title{
THE UNIVERSITY OF WARWICK
}

University of Warwick institutional repository: http://go.warwick.ac.uk/wrap

This paper is made available online in accordance with publisher policies. Please scroll down to view the document itself. Please refer to the repository record for this item and our policy information available from the repository home page for further information.

To see the final version of this paper please visit the publisher's website. Access to the published version may require a subscription.

Author(s): Michael Keall, Michael G Baker, Philippa HowdenChapman, Malcolm Cunningham, David Ormandy

Article Title: Assessing housing quality and its impact on health, safety and sustainability Year of publication: 2010

Link to published article:

http://dx.doi.org/10.1136/jech.2009.100701

Publisher statement: None 


\title{
Assessing housing quality and its impact on health, safety and sustainability
}

\author{
Michael Keall, ${ }^{1}$ Michael G Baker, ${ }^{1}$ Philippa Howden-Chapman, ${ }^{1}$ \\ Malcolm Cunningham, ${ }^{2}$ David Ormandy ${ }^{3}$
}

${ }^{1}$ He Kainga Oranga/Housing and Health Research Programme, University of Otago, Wellington, New Zealand ${ }^{2}$ BRANZ Ltd, Porirua,

New Zealand

${ }^{3}$ WHO Collaborating Centre for Housing Standards and Health School of Health and Social Studies, University of Warwick, Warwick, UK

\section{Correspondence to} Dr Michael Keall, He Kainga Oranga/Housing and Health Research Programme, University of Otago, 23A Mein Street, Newtown, Wellington 6242, New Zealand; michael.keall@otago.ac.nz.

Accepted 13 March 2010

\section{ABSTRACT}

Background The adverse health and environmental effects of poor housing quality are well established. A central requirement for evidence-based policies and programmes to improve housing standards is a valid, reliable and practical way of measuring housing quality that is supported by policy agencies, the housing sector, researchers and the public.

Methods This paper provides guidance on the development of housing quality-assessment tools that link practical measures of housing conditions to their effects on health, safety and sustainability, with particular reference to tools developed in New Zealand and England.

Results The authors describe how information on housing quality can support individuals, agencies and the private sector to make worthwhile improvements to the health, safety and sustainability of housing. The information gathered and the resultant tools developed should be guided by the multiple purposes and end users of this information. Other important issues outlined include deciding on the scope, detailed content, practical administration issues and how the information will be analysed and summarised for its intended end users. There are likely to be considerable benefits from increased international collaboration and standardisation of approaches to measuring housing hazards. At the same time, these assessment approaches need to consider local factors such as climate, geography, culture, predominating building practices, important housing-related health issues and existing building codes.

Conclusions An effective housing quality-assessment tool has a central role in supporting improvements to housing. The issues discussed in this paper are designed to motivate and assist the development of such tools.

\section{INTRODUCTION}

This paper describes a series of important issues that the authors have encountered in the development of tools to assess housing quality. Assessing housing quality is important because housing is a key determinant for health, safety and sustainability, and unless valid comparative measurements can be made, it is difficult to measure progress in improving the quality of the built environment.

This paper reviews both the purpose and scope of assessment tools, and considers practical issues that arise when they are administered. We present a framework for developing assessment tools in terms of their potential to contribute to health, safety and sustainability outcomes. We then briefly describe the experience with systematic housing quality assessment in England and New Zealand, together with an argument for standardisation of assessment methods, taking into account the unique aspects of each locality that affect health risks, building quality and sustainability outcomes.

\section{Importance of housing for health, safety and sustainability}

Housing is an important determinant of health. ${ }^{1-3}$ Substandard existing housing has been identified as a major public health issue in New Zealand, ${ }^{4}$ the $\mathrm{UK}^{5-7}$ the USA ${ }^{1}$ and Europe. ${ }^{89}$ Direct effects of poor housing have been identified on: injuries in the home, ${ }^{10}$ deaths from house fires, ${ }^{11}{ }^{12}$ respiratory symptoms, ${ }^{13}{ }^{14}$ coronary events ${ }^{15}$ and mental health problems. ${ }^{16-18}$ The importance of housing for health and safety is partly driven by the prolonged exposure people have to the home environment, an average of close to $16 \mathrm{~h}$ daily, a figure that is quite similar across different developed countries. $^{19} 20$

Features of substandard housing that have been identified as major concerns include: structural defects, inadequate insulation leading to dampness and mould; lack of heating and ventilation; lead; ${ }^{21}$ asbestos exposure (from deteriorating wall linings and cladding); volatile organic compounds (eg, from new carpeting); lack of safe drinking-water; ineffective waste disposal; inadequate facilities for food storage and preparation; household pests, such as ants, cockroaches, mice and rats; noise; and radon. ${ }^{22}$

The insulation and heating of a house, along with the prevailing weather, determines the efficiency with which a house can generate and retain heat for the occupants, as well as affecting mould growth and other respiratory hazards. Insulating housing is considered one of the most cost-effective measures to reduce carbon emissions, as insulated houses can reduce the demand for energy. ${ }^{23} 24$ Heating is also a major expense for households, expenditure that is largely wasted in houses with poor insulation and ineffective heating systems. ${ }^{25}$ Scarce household funds may therefore be spent on heat that is not usefully retained in the building, and the result may be exposure to excess cold and problems of damp and mould growth.

Sustainability is an important health issue because of the potentially disastrous health effects of climate change, to which housing contributes. ${ }^{26}$ In 2003 , the US residential sector produced more than $20 \%$ of total US energy-related $\mathrm{CO}_{2}$ emissions. ${ }^{27}$ Other important components of sustainability associated with housing include water usage, consumption of finite resources and production of toxic substances in building materials. 


\section{Purpose of a housing quality-assessment tool}

Assessment of house quality, including health, safety and sustainability, has two broad functions: first to provide a robust basis for policy development, compliance monitoring and research regarding the quality of housing stock; and second to assist house owners, renters, property managers and compliance agencies in making informed judgements about the management of individual properties.

Figure 1 shows how a robust assessment tool can play a core role in supporting these two broad functions. The central process involves measuring housing quality using a standardised tool.

The roles are represented by the numbers 1 to 8 in the figure. The first function aims to support policy makers, including local and central government, planners and regulators, public health officials, building designers, remediators, insurers, researchers, advocacy groups and others. The policy roles are as follows: (1) giving policy agencies robust data on the quality of housing stock and the impact of policies and compliance tools; (2) giving local authorities data on the quality of housing stock in their area to assess the effectiveness of their compliance tools and processes; (3) supporting research on the relationship between housing conditions and health, safety and sustainability outcomes; (4) translating research into improved evidence for policy makers regarding the impact of housing conditions; (5) ongoing validation and improvement of the assessment tool. In roles 1, 2, 4 and 6 (where action is taken in response to the measurements), the costs of remediating housing hazards or deficiencies need to be balanced against the costs (medical costs, costs of pain and suffering and loss of life quality and productivity) of adverse health/safety outcomes potentially prevented.

The second broad function of a robust housing qualityassessment tool is to guide decision-making about individual houses. This assessment could be in a regulatory context (eg, identification of substandard housing by local health authoritiesrole 6); a property management context (eg, helping providers of social housing identify properties in need of remediationrole 7); or to assist individuals in choosing a house to rent or buy (role 8). In theory, accurate quality information on which consumers base choices should lead to a demand for betterquality housing. In practice, consumers will balance such information against multiple considerations including resale potential and functionality. Some countries such as France require a certificate when a dwelling is offered for sale or rent to highlight potential hazards including lead and asbestos (see http://www.cibi.fr/eng_reports.html). In addition, all European countries now require an Energy Performance Certificate on sale or rent. ${ }^{28}$

A health and safety focused assessment approach can support rational investment in housing quality (role 4 in figure 1) by evaluating the cost of reducing/removing potential hazards compared with the cost saving to society. ${ }^{29}$ For example, research knowledge about the health effects of uninsulated, unheated, cold houses ${ }^{13}$ was incorporated into a New Zealand assessment tool (role 3 in figure 1). This knowledge raised awareness about the lack of insulation in most New Zealand houses and led to a national economic case being made for a large investment of public money for retrofitted insulation (role 4, where measurements inform policy formation). ${ }^{23}$

In England, the housing quality-assessment tool, the Housing Health and Safety Rating System (HH\&SRS), has been adopted as the statutory prescribed method for assessing conditions, primarily for the purpose of determining whether enforcement action by local councils is required to address potential hazards (role 6). ${ }^{30}$
Figure 1 How a measurement tool supports improved housing quality. Numbered roles relating to housing quality assessment are as follows. Policy and research on housing quality: (1) giving policy agencies data on the quality of housing stock and the impact of policies and compliance tools; (2) giving local authorities data on the quality of housing stock and effectiveness of compliance tools and processes; (3) supporting research on relationship between housing conditions and health, safety and sustainability outcomes; (4) translating research into improved evidence for policy makers about impact of housing conditions; (5) ongoing validation and improvement of the quality-assessment tool. Decisions about individual properties: (6) assisting local authorities identify substandard properties that require remediation; (7) assisting property owners, managers and others identify problems with specific properties that require remediation; (8) assisting individual buyers and renters in choosing a house.

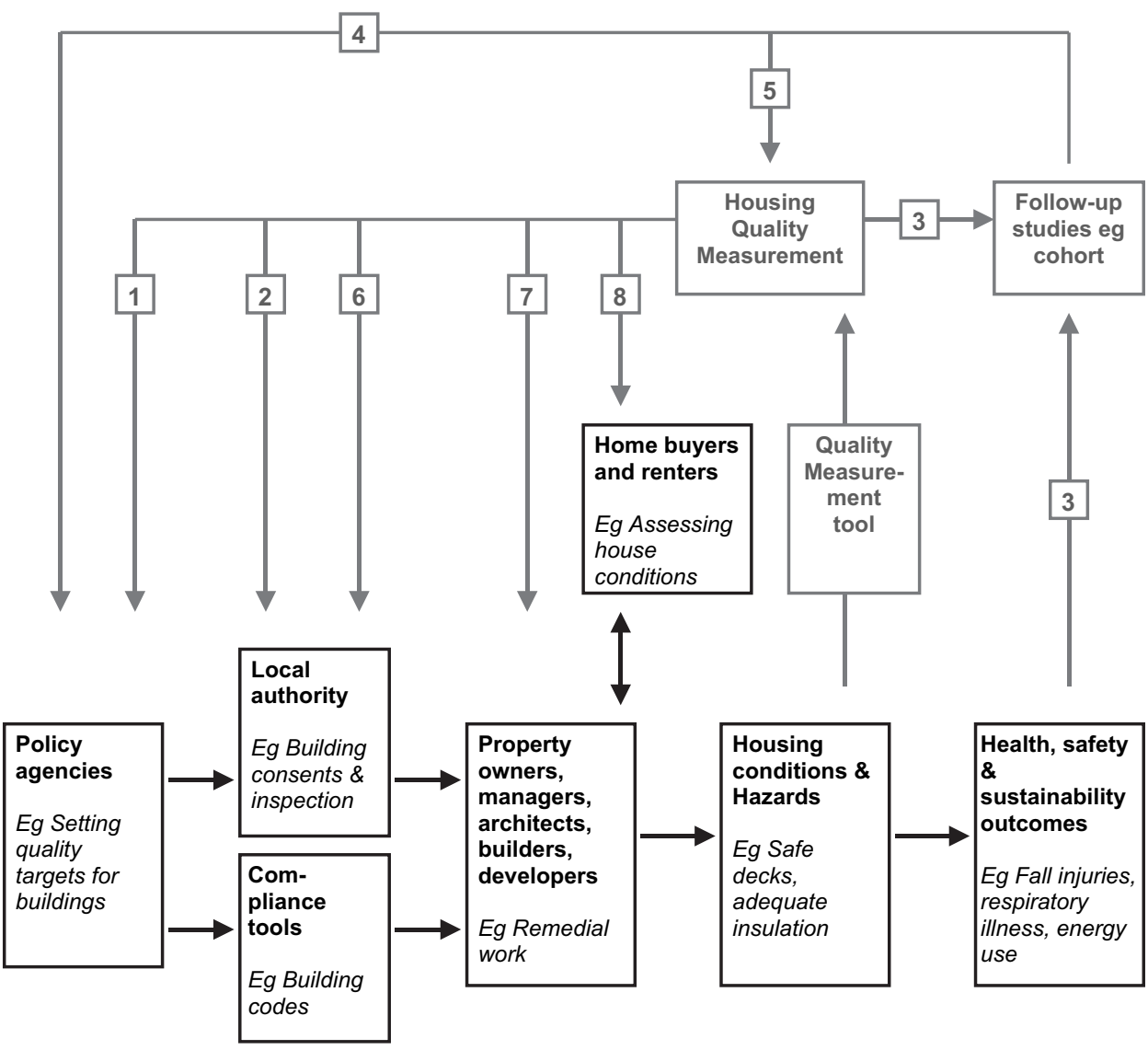




\section{Scope of a housing quality-assessment tool}

There are several scope issues that need to be resolved when considering the assessment of housing quality. Two of the most important to specify are the contextual level and outcome areas of housing quality. The contextual level recognises that the health, safety and sustainability outcomes we observe are a product of dwelling (housing) related factors as well as contributions from individual and household characteristics and features of the community and neighbourhood within wider regional, national and global contexts (see table 1 ).

Our view, reflected by the assessment tools the authors have developed for England and New Zealand, is that a housing quality-assessment tool should only measure features of the dwelling itself. This requirement immediately creates boundary issues that need to be resolved. Many health and safety hazards associated with housing can be seen as an interaction between the features of the house and the behaviour of the occupants. Some hazards, such as mould, can arise from both housing features and occupant behaviour. Even in housing with good ventilation, heating and insulation, the occupants can contribute to mould growth by not using ventilation facilities provided when cooking or bathing. Another example is household crowding, which facilitates the transmission of infectious diseases. ${ }^{31}$ Although this is rightly considered a housing-related health hazard, it is not exclusively a function of the dwelling itself.

There is a similar issue over whether the supply of services is essential to adequate housing. For example, if water or electricity is not available solely due to the fact that the occupant has not paid their bills, this does not constitute a failure of the building. However, the lack of any essential service for the house poses a health hazard. Deficiencies may also arise from lack of regulations to ensure adequate standards. For example, in New Zealand, landlords are not required to provide heating, and in England, a landlord only has to provide space for a refrigerator; the fridges are expected to be provided by the tenant.

Assessing the dwelling itself, rather than the occupier's behaviour in relation to the dwelling, has three advantages. First, the assessment stays relevant to the dwelling, even if there is a change of occupation. Second, if the assessment shows that the dwelling is safe for a member of a vulnerable group, whether or not such a person is in occupation, then the dwelling is safe for all potential occupants. For the English HH\&SRS, each housing hazard is assessed from the point of view of an age group most vulnerable to that hazard. ${ }^{30}$ Third, an unoccupied dwelling can be assessed.
Other instruments, for example the US Healthy Housing Inspection Manual, ${ }^{32}$ include some aspects of occupant behaviour, such as the use of extension power cords that pose fire risk. This approach is consistent with its aim to provide a '...reference tool for nurses, outreach workers, and others who are interested in preventing illness and injury due to residential health and safety hazards'. ${ }^{32}$ The manual has an aim of providing a resource that can be adapted for a range of purposes, and deliberately has a wide scope that includes occupant behaviour.

It is also necessary to consider the extent to which neighbourhood conditions and hazards should be included (see table 1). Some, such as air pollution, noise and the threat of violence, spill over from neighbourhoods and communities to become hazards experienced in the home. A secure home can become of greater importance in areas with high crime rates. Neighbourhood factors can therefore be included in an assessment tool to provide a context for housing features such as security. However, if the intent is to measure neighbourhood quality and its effects on health (and sustainability), it would be necessary to develop specific assessment tools for this purpose (which could potentially be administered along with housing quality assessment).

The second important scoping dimension shown in table 1 is the determination of the outcome areas covered by the qualityassessment tool. Although the original focus of the $\mathrm{New}$ Zealand tool was on health outcomes, we have become increasingly aware of the importance of safety and sustainability. Many features of housing quality (such as insulation) contribute simultaneously to different health, safety and sustainability outcomes.

Once the purpose and scope of the tool have been set in the context of existing regulatory frameworks, a detailed framework linking housing quality features with relevant health, safety and sustainability outcomes needs to be developed, such as that presented in table 2 .

\section{Practical issues in administration of a housing quality-assessment tool}

The assessment tool needs to be reliable, practical and affordable to use. Some of the issues regarding the administration of the tool are as follows:

- Expense: Time-consuming or expensive measurements (that require laboratory testing, expensive equipment or extensive expertise) should be included only if they are essential for detecting and quantifying the hazard (eg, lead, radon, carbon monoxide). There would also need to be correspondingly

Table 1 Levels of the built environment and their influences on health, safety and sustainability

\begin{tabular}{|c|c|c|}
\hline \multirow[b]{2}{*}{ Level of built environment } & \multicolumn{2}{|l|}{ Outcome areas } \\
\hline & Influences on health and safety & Influences on sustainability \\
\hline Global, national, regional levels & $\begin{array}{l}\text { Policy, socio-economic and cultural influences beyond the } \\
\text { neighbourhood level }\end{array}$ & Policy and economic influences-for example, Kyoto Protocol \\
\hline Neighbourhood & $\begin{array}{l}\text { Physical features such as air pollution, road safety, urban } \\
\text { design, transportation, amenities }\end{array}$ & $\begin{array}{l}\text { Urban design, waste and water management and transport } \\
\text { infrastructure }\end{array}$ \\
\hline Community & $\begin{array}{l}\text { Social, cultural and economic aspects such as social capital, } \\
\text { safety from crime, civic capacity }\end{array}$ & Willingness to invest in infrastructural and behavioural change \\
\hline Dwelling & $\begin{array}{l}\text { Physical quality of building such as insulation and safety } \\
\text { features }\end{array}$ & $\begin{array}{l}\text { Ability of the dwelling to use water and energy efficiently } \\
\text { to support the daily life of the occupants }\end{array}$ \\
\hline Household & $\begin{array}{l}\text { Social, cultural and economic aspects such as affordability, } \\
\text { suitability, security of tenure }\end{array}$ & $\begin{array}{l}\text { Requirements of the household in terms of space, energy, } \\
\text { water and transport }\end{array}$ \\
\hline Individuals & $\begin{array}{l}\text { Demographic, psychological and biological features, including } \\
\text { knowledge and attitudes }\end{array}$ & $\begin{array}{l}\text { Cultural and lifestyle characteristics such as willingness to } \\
\text { recycle and use sustainable options in transport }\end{array}$ \\
\hline
\end{tabular}

The area in bold shows the elements included in the assessment tools developed in England and New Zealand. 
Table 2 Links between housing quality features (and their associated hazards and methods of measurement by the New Zealand housing quality measurement tool) and likely outcomes (health, safety and sustainability)

\begin{tabular}{|c|c|c|c|}
\hline Housing quality feature measured & Hazards associated with housing & Method of measurement & $\begin{array}{l}\text { Health, safety and sustainability } \\
\text { outcomes }\end{array}$ \\
\hline $\begin{array}{l}\text { Adequate structural soundness: } \\
\text { Adequate foundations } \\
\text { Adequate walls, floors } \\
\text { Adequate roof, cladding }\end{array}$ & Structural collapse and falling elements $\dagger$ & $\begin{array}{l}\text { Visual inspection by trained assessor } \\
\text { Measurement of key dimensions (some } \\
\text { structural elements) }\end{array}$ & Injury following natural disaster \\
\hline
\end{tabular}

Adequate windows

Adequate stairs

Adequate chimneys

Adequate internal walls

Cylinders and header tanks have

earthquake restraints

\section{Adequate water supply:}

Adequate potable water

Adequate water for non-potable uses

\section{Adequate sanitary areas and waste} disposal:

Sanitary and functional toilet

Adequate personal washing facilities and

hot water Sanitary and functional facilities

for clothes washing.

Adequate solid waste storage and collection

Safe and functional sewage disposal

Safe and function storm water, surface

water and ground water disposal

Adequate food preparation areas:

Safe and functional cooking device

Adequate space/area for food preparation

and cleaning, hot water

Adequate safe space for food storage

Adequate safety from falls and other

injuries:

Safe bath and shower areas

Safe decks, surfaces, barriers

Safe stairs, treads, risers

Safe window sills

Safe handrails and grabrails

Safe floor areas

Safe outside paths and steps

Safe doors and windows

Adequate fencing of section

Adequate fencing of pool

Good location and operability of amenities

Adequate safety from fires,

electrocution and explosion:

Safe and functional energy source

Safe and functional electrical and gas

installations

Safe and functional wood burner, fire

place, chimneys ${ }^{33}$

Smoke alarms ${ }^{34}$

Adequate escape route and exit ways

Hot water less than $55^{\circ} \mathrm{C}$

Adequate warmth and dryness:

Optimal orientation

Adequate insulation

Adequate draft stopping

Adequate heating

Adequate site/subfloor drainage ${ }^{35} 36$

Adequate ventilation

Minimum indoor temperature

Adequate protection from excess heat:

Optimal orientation and shading

Adequate insulation

Adequate ventilation

Safe heating facilities

Safe cooking facilities

Adequate lighting and sunlight:

Adequate natural lighting

Adequate artificial lighting
Inadequate or contaminated water supply

Infection from poor hand-washing and sewage

Infection from pests (rodents, flies, etc)

Infection from contaminated food

Falls associated with baths, etc

Falling on level surfaces, etc

Falling on stairs, etc

Falling between levels

Vehicle injuries in driveways

Drowning in pools

Collision and entrapment

Poor ergonomics and operation of

amenities

\section{Electrical hazards}

Fire

Flames, hot surfaces, etc

Explosions

Damp and mould growth ${ }^{37}$

Excess cold ${ }^{13}$

Excess heat

Inadequate or excessive lighting

Inadequate sunlight exposure
Visual inspection by trained assessor Source of water

Treatment method of water, if not reticulated

Visual inspection by trained assessor including subfloor inspection

Test water temperature at hot tap Evidence of pests
Visual inspection by trained assessor

Visual inspection by trained assessor Test water temperature at hot tap Type and safety of cooking device Surface area and quality of food preparation area

Visual inspection by trained assessor Measurement of key dimensions (stairs, decks, windows, handrails, paths, pools and fences)

Visual inspection by trained assessor Test water temperature at hot tap Test smoke detectors

Visual inspection by trained assessor Measure thickness of ceiling insulation

Visual inspection by trained assessor Measurement of light intensity Test of moisture levels in walls
Enteric infections

Enteric infections

Enteric infections

Injuries and avoidable deaths in home $\ddagger$

Burns, scalds, electrocutions and avoidable deaths in home

Excess winter hospitalisations and deaths Asthma

Excess summer hospitalisations and deaths

Falls at home

Reduced sleep and psychological wellbeing

Vitamin D deficiency and associated illnesses 
Table 2 Continued

\begin{tabular}{|c|c|c|c|}
\hline Housing quality feature measured & Hazards associated with housing & Method of measurement & $\begin{array}{l}\text { Health, safety and sustainability } \\
\text { outcomes }\end{array}$ \\
\hline $\begin{array}{l}\text { Adequate control of indoor pollutants: } \\
\text { Minimum asbestos products } \\
\text { No lead paint } \\
\text { Water pipes free from lead } \\
\text { Minimum combustion products } \\
\text { Minimum VOCs }\end{array}$ & $\begin{array}{l}\text { Asbestos and manufactured mineral fibres } \\
\text { Lead paint, }{ }^{38-41} \text { pipes }{ }^{42} \\
\text { Biocides (eg, timber treatments) } \\
\text { Carbon monoxide and fuel combustion } \\
\text { products } \\
\text { Uncombusted fuel gas } \\
\text { Volatile Organic compounds-for } \\
\text { example, formaldehyde } \\
\text { Radiation* }\end{array}$ & $\begin{array}{l}\text { Visual inspection by trained assessor- } \\
\text { especially noting where building material } \\
\text { has deteriorated, releasing fibres into the } \\
\text { air } \\
\text { Testing of paint for lead content } \\
\text { Measurement of VOCs with hand-held } \\
\text { device (although the concentration is } \\
\text { highly variable over time, making them } \\
\text { difficult to measure }{ }^{43} \text { ) }\end{array}$ & $\begin{array}{l}\text { Acute toxicity or asphyxiation } \\
\text { Respiratory illnesses } \\
\text { Range of chronic illnesses }\end{array}$ \\
\hline $\begin{array}{l}\text { Adequate protection from noise: } \\
\text { Minimum internal noise sources } \\
\text { Adequate insulation from external noise } \\
\text { sources }\end{array}$ & Noise & $\begin{array}{l}\text { Visual and aural inspection by trained } \\
\text { assessor }\end{array}$ & $\begin{array}{l}\text { Reduced sleep }{ }^{7} \text { and psychological well- } \\
\text { being } \\
\text { Potential chronic illnesses } \S\end{array}$ \\
\hline $\begin{array}{l}\text { Adequate security, privacy and space: } \\
\text { Secure windows and doors } \\
\text { Adequate privacy from neighbours } \\
\text { Adequate space for personal activities } \\
\text { such as study }\end{array}$ & $\begin{array}{l}\text { Entry by intruders } \\
\text { Inadequate space } \\
\text { Inadequate privacy }\end{array}$ & $\begin{array}{l}\text { Visual inspection by trained assessor } \\
\text { Measurement of floor area }\end{array}$ & $\begin{array}{l}\text { Assaults at home } \\
\text { Reduced sleep and psychological well- } \\
\text { being } \\
\text { Impaired educational attainment }\end{array}$ \\
\hline $\begin{array}{l}\text { Addresses energy efficiency: } \\
\text { Adequate insulation } \\
\text { Optimal orientation to sun } \\
\text { Effective, sustainable heating } \\
\text { Sustainable and non-polluting energy } \\
\text { sources (eg, solar water heating) }\end{array}$ & $\begin{array}{l}\text { Environmental degradation (global } \\
\text { warming; depletion of natural resources; } \\
\text { environmental pollution) }\end{array}$ & $\begin{array}{l}\text { Visual inspection of insulation in ceiling, } \\
\text { walls, floor } \\
\text { All heating sources listed }\end{array}$ & Environmental well-being \\
\hline $\begin{array}{l}\text { Adequate sustainability of water use } \\
\text { and waste disposal: } \\
\text { Water-saving technology } \\
\text { Collection and reuse system for rainwater } \\
\text { Sustainable sewage disposal } \\
\text { Specific area for storage of recycling }\end{array}$ & $\begin{array}{l}\text { Environmental degradation (global } \\
\text { warming; depletion of natural resources; } \\
\text { environmental pollution) }\end{array}$ & $\begin{array}{l}\text { Collection of rainwater not currently noted } \\
\text { Visual inspection of stormwater and site } \\
\text { drainage }\end{array}$ & Environmental well-being \\
\hline
\end{tabular}

\footnotetext{
*Radon is a significant cause of cancer in Europe ${ }^{44}$ but barely present in countries with geologies such as New Zealand.

†Earthquake hazards not addressed in much detail in the British Housing Health and Safety Rating System, as earthquakes rare in the UK-they are covered by Hazard No 29, Structural Collapse and Falling Elements.

$\ddagger$ All injury hazards, with the exception of drowning hazards, are included in the English Housing Health and Safety Rating System.

§http://www.telegraph.co.uk/news/main.jhtml?xml=/news/2007/08/23/noise123.xml
}

important health effects that can be realistically reduced as a consequence of the measurements made (see Method of Measurement listed in table 2).

- Safety is important: An earlier version of the HHI involved inspectors unscrewing electricity outlets to see whether the walls were insulated or not. Subsequent versions dispensed with this step to avoid the potential for electric shocks and fires initiated by disturbing the wiring. There are many such safety issues to be considered.

- Training required should not be too demanding, for cost reasons. However, in the case of the New Zealand HHI, a background in the building (or related) trade was found to be a minimum prerequisite for the housing inspector. ${ }^{45}$ The English HH\&SRS has the advantage of a well-established network of environmental health practitioners, who have sufficient background and experience to make the sorts of judgements required for the system.

- Quality assurance is vital to ensure the assessments are valid and reliable, particularly for those items requiring expert judgement. Related to the importance of peer review, it is useful to make ratings of the same dwelling using different inspectors to measure inter-rater reliability.

\section{Summary measures from a housing quality-assessment tool}

The data collected by a housing quality-assessment tool will always need a carefully considered method to turn them into usable information. The method used to summarise these data depends on the purpose of the quality rating process and the end users (see figure 1).

There are quite sophisticated methods available to estimate the environmental burden of disease that can be attributed to specific exposures, at a population level. ${ }^{46}$ In theory, such tech- niques could be applied to all housing hazards to estimate the health burden of each, measured using a standard metric such as disability-adjusted life years (DALYs). The health and safety impact of a house can then be quantified as the sum of the impact of the hazards it contains. Summary measures of the health rating of housing are still complicated by the wide range of potential hazards, the complexity of the dose-response relationship and the relatively small evidence base. Consequently, available tools have tended to rely on expert judgement or to be narrow in focus.

An example of a rating system based on expert judgements is the English HH\&SRS, which uses a hazard-weighted approach to summarise housing quality. It uses trained environmental health practitioners to assess the presence and degree of housing hazards and the likelihood that they could lead to some adverse health consequence over the next 12 months.

An example of a New Zealand summary measure based on research evidence for housing safety has been documented in more detail in Keall et al. ${ }^{10}$ There was found to be a relationship between a summary measure that was a count of particular home injury hazards and the occurrence of injury such that each additional home hazard identified increased the odds of a home injury by $22 \%{ }^{10}$

\section{DISCUSSION}

The overall goal of developing a housing quality-assessment tool is to improve housing, but this goal is often achieved indirectly. One example is the English HH\&SRS, which is the statutory prescribed method for improving rental housing conditions via (the threat of) enforcement action by local councils (role 6 in figure 1). ${ }^{30}$ To our knowledge, there are few other examples of 
housing quality assessment that explicitly focus on the improvement of housing conditions which have resultant health/safety/sustainability outcomes.

The utility of housing quality-assessment tools is currently limited by their lack of widespread use and inconsistency across jurisdictions. Internationally, the approach to assessing housing quality could be described as fragmented, reflecting a lack of national agreement about what is important in housing quality. The USA, for example has several different housing hazard assessment protocols. ${ }^{47}$ This situation can be contrasted to international agreed standards regarding sustainability, for example. ${ }^{48}$ Fragmentation is also a barrier in terms of knowledge of links between housing and health, which spans many disciplines, and in terms of the wide variety of stakeholders, with different interests and sometimes disparate responsibilities. ${ }^{49}$ Another contributing reason for lack of regulation and consistency of standards probably lies in the attitude to housing as a private space that needs to be respected and the different legal responsibilities placed on owners and on occupiers by leases and contracts. ${ }^{48}$

Cost is another important barrier. The vast amount of data typically collected by housing assessment tools means that a considerable amount of time is required for the house inspection, which may increase the expense beyond a point where the assessment could be generally acceptable. Hasselaar ${ }^{50}$ reviewed housing assessment instruments in Europe, finding that some cost as much as $€ 1500$ per house, which could potentially restrict widespread use of the instrument. There are other barriers to the uptake of housing quality-assessment tools, ranging from cultural barriers, including the sense that one's home is private and should not be subjected to assessment, to lack of agreement on the purposes and benefits of the qualityassessment tool at the political level. Governmental engagement and support are essential for the widespread use of an assessment tool.

Although consistency is a desirable attribute of housing assessment tools, they must also reflect the requirements of different jurisdictions, related to local hazards (including climate), predominate housing types and existing regulatory frameworks, as summarised in the methods section. Quality assessment of resilience to earthquakes, an important feature in seismically active countries such as New Zealand, Japan and the west coasts of both North and South America, is not so important in other parts of the world. Also, differences in climate produce different hazards. For example, New Zealand housing tends to be oriented to collect sunlight, as cold temperatures are regarded as more of a hazard than are hot temperatures; in hotter parts of Spain, glazing that collects sunlight is avoided, as excess heat is a serious hazard. These examples highlight the fact that whereas there are some aspects of housing quality that can be standardised (eg, safety from falls and fires), there are others that need to differ from jurisdiction to jurisdiction to reflect desirable features of healthy, safe and sustainable housing in that locality. The importance of a common approach to housing health, safety and environmental issues is that it can lead to consistency in public health action and hence greater public health equity. ${ }^{49}$

\section{CONCLUSION}

Housing quality has a fundamental effect on health, safety and sustainability. It is therefore vital for the advancement of public health that it is satisfactorily assessed. Assessment can lead to housing improvement via effective housing policy-based on robust evidence about housing quality-and a well-informed

\section{What is already known on this subject}

A central requirement for evidence-based policies and programmes is adequate surveillance of potential harmful exposures. Housing is an important contributor to the burden of disease and injury, but data on housing quality are lacking in most jurisdictions. This is at least partially a consequence of lack of agreement about what aspects of quality to measure, methods of measurement and how to use this information to benefit housing quality and consequent health and safety outcomes.

\section{What this study adds}

We provide a context for the role of housing quality assessment in the development of policies and interventions and argue for more comprehensive evidence-based quality-assessment regimes. The motivation and resultant funding for developing and applying housing quality-assessment methods is maximised when the information gathered and the resultant tools developed are guided by multiple purposes and a variety of end users.

housing market where consumers have knowledge about the quality of the housing they are renting and buying.

There are likely to be considerable benefits from increased international collaboration and standardisation of approaches to assessing housing quality. At the same time, these assessment approaches need to consider local factors such as climate, geography, culture, predominate building practices, important housing-related health issues and existing building codes. The issues discussed in this paper are designed to assist the developers of such tools based on the experiences gained in England and New Zealand.

Acknowledgements Thanks are due to $D$ Jacobs for his thoughtful and helpful comments on an earlier draft.

Funding He Kainga Oranga/Housing and Health Research Programme is funded by the New Zealand Health Research Council.

Competing interests None.

Provenance and peer review Not commissioned; externally peer reviewed.

\section{REFERENCES}

1. Krieger J, Higgins D. Housing and health: time again for public health action. $A m \mathrm{~J}$ Public Health 2002;92:758-68.

2. Mackenbach J, Howden-Chapman P. Housing, neighbourhoods and health. Eur $\mathrm{J}$ Public Health 2002;12:161-2.

3. Howden-Chapman P. Housing standards: a glossary of housing and health. J Epidemiol Community Health 2004;58:162-8.

4. Howden-Chapman P, Carroll P, eds. Housing and health: research, policy and innovation. Wellington: Roger Steele, 2004:83-5.

5. Thomson H, Petticrew M, Morrison D. Health effects of housing improvement: systematic review of intervention studies. BMJ 2001;323:187-90.

6. Acheson D. Independent inquiry into inequalities in health report. London: HMSO, 1998.

7. British Medical Association. Housing and health: building for the future. London: British Medical Association, 2003.

8. Healy JD. Housing, fuel poverty and health: a pan-European analysis. Aldershot: Ashgate, 2004

9. WHO Regional Office for Europe. LARES: large analysis and review of European housing and health Status. Bonn: European Centre for Environment and Health, WHO Regional Office for Europe, 2006.

10. Keall MD, Baker M, Howden-Chapman P, et al. Association between the number of home injury hazards and home injury. Accid Anal Prev 2008;40:887-93. 
11. Istre GR, McCoy MA, Osborn L, et al. Deaths and injuries from house fires. N Engl J Med 2001;344:1911-16

12. Peek-Asa C, Zwerling C. Role of environmental interventions in injury control and prevention. Epidemiol Rev 2003;25:77-89.

13. Howden-Chapman P, Matheson A, Crane J, et al. Effect of insulating existing houses on health inequality: cluster randomised study in the community. BMJ 2007;334:460

14. Howden-Chapman P, Pierse N, Nicholls S, et al. Effects of improved home heating on asthma in community dwelling children: randomised community study. BMJ 2008;337:a1411.

15. Dedman DJ, Gunnell D, Davey Smith G, et al. Childhood housing conditions and later mortality in the Boyd Orr cohort. J Epidemiol Community Health 2001;55:10-15.

16. Evans GW. The built environment and mental health. J Urban Health 2003;80:536-55.

17. Fredouille J, Laporte E, Mesbah M, et al. Housing and mental health. Housing and health in Europe. Abingdon and New York: Routledge, 2009

18. Freeman HL, ed. Mental health and the environment. London: Churchill, Livingstone, 1984.

19. Baker M, Keall M, Au EL, et al. Home is where the heart is-most of the time. N Z Med J 2007;120:U2769.

20. Leech JA, Nelson WC, Burnett RT, et al. It's about time: a comparison of Canadian and American time-activity patterns. J Expo Anal Environ Epidemiol 2002;12:427-32.

21. WHO. Lead and health. Health and environment briefing pamphlet series 1 . Copenhagen: WHO, 1995

22. Wilkinson D. Poor housing and ill health: a summary of research evidence. The Scottish Office: Central Research Unit, 1999.

23. Chapman R, Howden-Chapman P, Viggers $\mathrm{H}$, et al. Retrofitting houses with insulation: a cost-benefit analysis of a randomised community trial. J Epidemiol Community Health 2009;63:271-7.

24. The Economist. Irrational incandescence. Economist 2007

25. Howden-Chapman $\mathbf{P}$, Viggers $\mathrm{H}$, Chapman $\mathrm{R}$, et al. Warm homes: drivers of demand for heating in the residential sector in New Zealand. Energy Policy 2009;37:3387-399.

26. Wilkinson $\mathbf{P}$, Smith KR, Beevers $\mathrm{S}$, et al. Energy and health 4: Energy, energy efficiency, and the built environment. Lancet 2007;370:1175-87.

27. Energy Information Administration. Emissions of greenhouse gases in the United States 2003. Washington, DC: Energy Information Administration, 2004.

28. COM 2002/91/EC. Directive on the Energy Performance of Buildings. 2002

29. Davidson M, Roys R, Nicol S, et al. The real cost of poor housing. Watford, England: BRE Publications, BRE Trust, 2009.

30. Ormandy DA. Health based approach to the assessment of unsatisfactory housing - the UK's Housing Health \& Safety Rating System. Forli, Italy: WHO Housing \& Health Symposium, 2002
31. Baker M, McNicholas A, Garrett N, et al. Household crowding a major risk factor for epidemic meningococcal disease in Auckland children. Pediatr Infect Dis $J$ 2000;19:983-90

32. Centers for Disease Control and Prevention, US Department of Housing and Urban Development. Healthy housing inspection manual. Atlanta: US Department of Health and Human Services, 2008.

33. Woodside A, Cunningham M. Open fireplaces and insert solid fuel stoves-an experimental and analytical study. Study Report No 26. Porirua City: BRANZ, 1990

34. Wade C, Duncan J. Cost-effective fire safety measures for residential buildings in New Zealand. Porirua City: BRANZ, 2000.

35. Airaksinen $\mathbf{M}$, Pasanen $\mathrm{P}$, Kurnitski $\mathrm{J}$, et al. Microbial contamination of indoor air due to leakages from crawl space: a field study. Indoor Air 2004;14:55-64.

36. Su H, Rotnitzky A, Burge $\mathrm{H}$, et al. Examination of fungi in domestic interiors by using factor analysis: correlations and associations with home factors. Appl Environ Microbiol 1992;58:181-6

37. Fisk WJ, Lei-Gomez Q, Mendell MJ. Meta-analyses of the associations of respiratory health effects with dampness and mold in homes. Indoor Air 2007:17:284-96.

38. Samet JM, Marbury MC, Spengler JD. Health effects and sources of indoor air pollution. Am Rev Respir Dis 1987;136:1486-508.

39. Warren C. Brush with death: a social history of lead paint. Baltimore: John Hopkins University, 2000.

40. Bellinger D, Leviton A, Waternaux C, et al. Low-level lead exposure, social class and infant development. Neurotoxicol Teratol 1993:10:497-503.

41. Sharfstein J, Sandel M, Kahn RS, et al. Is child health at risk while families wait for housing vouchers? Am J Public Health 2001;91:1191-2.

42. Needleman $\mathbf{H}$, Gatsonis C. Low level lead exposure and the IO of children. J Am Med Assoc 1990;263:673-8.

43. Sundell J. On the history of indoor air quality and health. Indoor Air 2004:14:51-8

44. WHO, Radon. Health and the environment briefing pamphlet series 10. Copenhagen: World Health Organization, 1996

45. Keall MD, Baker M, Howden-Chapman P, et al. Healthy Housing Index Pilot Study Final Report March 2007. Wellington: Housing and Health Research Programme, 2007.

46. Kay D, Prüss A, Corvalán C. Methodology for assessment of Environmental burden of disease. Geneva: World Health Organization, 2000.

47. Jacobs DE. A qualitative review of housing hazard assessment protocols in the United States. Environ Res 2006;102:13-21.

48. Jacobs DE. Healthy housing standards: fragmentation or harmonization. 5th Warwick Healthy Housing Conference. Warwick: 2008.

49. Adan OCG, Ng-A-Tham J, Hanke W, et al. In search of a common European approach to a healthy indoor environment. Environ Health Perspect 2007:115:983-8

50. Hasselaar E. Checklist healthy housing for tenants and home owners. In: Bonnefoy $X$ ed. The Second WHO International Housing and Health Symposium. Vilnius, Lithuania: WHO Europe, 2004:93-103. 